\title{
BARBEAU, Marius, Trésor des anciens Jésuites. Bulletin no 153 — no 43 de la Série anthropologique. Publié avec l'autorisation de l'Honorable Alvin Hamilton, ministre du nord canadien et des ressources nationales. Musée national du Canada. Edmond Cloutier, c.m.g., o.a., d.s.p., Imprimeur de la Reine et contrôleur de la papeterie, Ottawa, 1957. In-8, 242 p. $\$ 1.50$. Couverture dessinée et cartonnée.
}

\section{Lionel Groulx}

Volume 12, numéro 1, juin 1958

URI : https://id.erudit.org/iderudit/301893ar

DOI : https://doi.org/10.7202/301893ar

Aller au sommaire du numéro

Éditeur(s)

Institut d'histoire de l'Amérique française

ISSN

0035-2357 (imprimé)

1492-1383 (numérique)

Découvrir la revue

Citer ce compte rendu

Groulx, L. (1958). Compte rendu de [BARBEAU, Marius, Trésor des anciens Jésuites. Bulletin no 153 - no 43 de la Série anthropologique. Publié avec l'autorisation de l'Honorable Alvin Hamilton, ministre du nord canadien et des ressources nationales. Musée national du Canada. Edmond Cloutier, c.m.g., o.a., d.s.p., Imprimeur de la Reine et contrôleur de la papeterie, Ottawa, 1957. In-8, 242 p. \$1.50. Couverture dessinée et cartonnée.] Revue d'histoire de l'Amérique française, 12(1), 138-139. https://doi.org/10.7202/301893ar d'utilisation que vous pouvez consulter en ligne. 
Barbeau, Marius, Trésor des anciens Jésuites. Bulletin no 153 - no 43 de la Série anthropologique. Publié avec l'autorisation de l'Honorable Alvin Hamilton, ministre du nord canadien et des ressources nationales. Musée national du Canada. Edmond Cloutier, c.m.g., o.a., d.s.p., Imprimeur de la Reine et contrôleur de la papeterie, Ottawa, 1957. In-8, 242 p. $\$ 1.50$. Couverture dessinée et cartonnée.

Une «Table des matières » (III-X), placée au début de l'ouvrage, nous indique déjà les richesses inventoriées. Trois parties: I. - En quoi consistait le trésor des anciens Jésuites; II. Catalogue raisonné (de ce trésor) ; III. - Appendice: Tableau des secours accordés à l'Hôpital Général de Québec - Mobilier des Jésuites, documents conservés aux Archives publiques du Canada.

La première partie (1-37), de la plume de M. Marius Barbeau, pourrait s'intituler prologue ou introduction. Un inventaire sommaire nous détaille la réelle richesse du Trésor. Richesse variée: objets de culte, parements d'autels, argenterie, images, statues, églises, chapelles; manuscrits: Relations des Jésuites, journal, registres, lettres, glossaires, grammaires en langue huronne-iroquoise, algonquine, livres, légendes des Jésuites. Les Jésuites de l'ancien régime ont laissé, au Canada, conclut M. Barbeau, «un souvenir ineffaçable ». Leur «Trésor » fournit ... la meilleure preuve possible des connaissances, des talents, des goûts prononcés pour le savoir, les beaux arts et la science de ces propagandistes en chef de la supériorité latine en Amérique. »

La deuxième partie, le «Catalogue raisonné », confirme la louangeuse affirmation. Y défilent, en effet, en près de 200 pages (39-231), la présentation et description des argenteries, des ornements brodés, des hauts reliefs et parements sculptés, retables, tabernacles, balustrades, chaires, statues de bois, reliquaires, wampums, meubles, objets en métal ou en ivoire, tableaux, images, manuscrits, livres, légendes: toutes choses laissées par les Jésuites et retrouvées au Canada. Résumer ici quoi que ce soit est chose impossible. Notons cependant que chaque objet, ou peu s'en faut, s'accompagne d'une gravure et d'une note historique de l'auteur.

La troisième partie de l'ouvrage ou «Appendice» se compose de notes d'archives ou de documents cités au texte, documents conservés aux Archives publiques du Canada sur les biens des Jésuites.

Inventaire merveilleux. On croirait feuilleter le catalogue d'un musée de grand style. Après avoir parcouru le «Trésor des anciens Jésuites », nul ne saurait plus douter de la qualité de la civilisation implantée en Nouvelle-France, par la Compagnie de 
Jésus. Un tel livre n'intéresse pas seulement les artistes, mais, au premier chef et grandement les historiens. Et sans peine l'on souscrit à cette autre affirmation de l'auteur: «Le trait qui caractérise avant tout les anciens Jésuites du nouveau monde fut leur adaptation graduelle au milieu géographique nord-américain, en conservant plus que toute autre corporation religieuse le riche héritage de la catholicité et de la culture européenne ».

\section{LIONEL GROULX, ptre}

